\title{
PAI-1 promoter 4G/5G polymorphism (rs1799768) contributes to tumor susceptibility: Evidence from meta-analysis
}

\author{
XIN XU, YANQI XIE, YIWEI LIN, XIANGLAI XU, YI ZHU, YEQING MAO, ZHENGHUI HU, \\ JIAN WU, HONG CHEN, XIANGYI ZHENG, JIE QIN and LIPING XIE \\ Department of Urology, First Affiliated Hospital, School of Medicine, \\ Zhejiang University, Hangzhou, Zhejiang 310003, P.R. China
}

Received June 2, 2012; Accepted September 28, 2012

DOI: $10.3892 /$ etm.2012.734

\begin{abstract}
Plasminogen activator inhibitor-1 (PAI-1), belonging to the urokinase plasminogen activation (uPA) system, is involved in cancer development and progression. The PAI-1 promoter $4 \mathrm{G} / 5 \mathrm{G}$ polymorphism was shown to contribute to genetic susceptibility to cancer, although the results were inconsistent. To assess this relationship more precisely, a meta-analysis was performed. The electronic databases PubMed, Scopus, Web of Science and Chinese National Knowledge Infrastructure (CNKI) were searched; data were extracted and analyzed independently by two reviewers. Ultimately, 21 eligible case-control studies with a total of 8,415 cancer cases and 9,208 controls were included. The overall odds ratio (OR) with its $95 \%$ confidence interval (CI) showed a statistically significant association between the PAI-1 promoter $4 \mathrm{G} / 5 \mathrm{G}$ polymorphism and cancer risk $(4 \mathrm{G} / 4 \mathrm{G}$ vs. 5G/5G: $\mathrm{OR}=1.25,95 \% \mathrm{CI}=1.07-1.47, \mathrm{P}_{\text {heterogeneity }}=0.001$; $4 \mathrm{G} / 4 \mathrm{G}$ vs. $4 \mathrm{G} / 5 \mathrm{G}+5 \mathrm{G} / 5 \mathrm{G}: \mathrm{OR}=1.10,95 \% \mathrm{CI}=1.03-1.17$, $\mathrm{P}_{\text {heterogeneity }}=0.194 ; 4 \mathrm{G} / 4 \mathrm{G}+4 \mathrm{G} / 5 \mathrm{G}$ vs. $5 \mathrm{G} / 5 \mathrm{G}: \mathrm{OR}=1.17$, $95 \% \mathrm{CI}=1.01-1.35, \mathrm{P}_{\text {heterogeneity }}=0.041$ ). In further subgroup analyses, the increased risk of cancer was observed in a subgroup of Caucasians with regards to endometrial cancer. Our meta-analysis suggests that the PAI-1 4G/5G polymorphism most likely contributes to susceptibility to cancer, particularly in Caucasians. Furthermore, the 4G allele may be associated with an increased risk of endometrial cancer.
\end{abstract}

\section{Introduction}

Despite many years of primary and clinical research aimed at curbing tumor growth, metastasis remains the main cause of mortality in cancer patients (1). During recent years, mounting

Correspondence to: Dr Liping Xie, Department of Urology, First Affiliated Hospital, School of Medicine, Zhejiang University, 79 Qingchun Road, Hangzhou, Zhejiang 310003, P.R. China E-mail: xielp@zjuem.zju.edu.cn

Key words: plasminogen activator inhibitor-1, carcinoma, genetic polymorphism, susceptibility, meta-analysis evidence has shown that plasminogen activator inhibitor-1 (PAI-1), belonging to the urokinase plasminogen activation (uPA) system, plays an important role in signal transduction, cell adherence and cell migration, thus promoting invasion and metastasis (2). In addition, PAI-1 concentrations and mRNA levels in primary tumor tissues correlate with adverse patient outcome in multiple cancer types (3-6). Recently, the first level-of-evidence-1 (LOE-1) cancer biomarker, PAI-1, entered clinical practice in breast cancer management (7).

The PAI-1 gene is located on chromosome 7 and contains 8 introns and 9 exons (8). Gene variability may contribute to the level of PAI-1 biosynthesis. Among the variants of the PAI-1 gene, the PAI-1 4G/5G polymorphism (rs1799768) has been the most frequently studied. The $4 \mathrm{G}$ allele of $4 \mathrm{G} / 5 \mathrm{G}$ insertion/deletion polymorphism located in the promoter region $675 \mathrm{bp}$ upstream from the transcription start sequence of the PAI-1 gene is responsible for higher plasma PAI-1 levels, conditioning a clear hypofibrinolytic state (9). Several studies $(10,11)$ have shown that the $4 \mathrm{G}$ allele has greater activity than the $5 \mathrm{G}$ allele and that higher frequencies of the $4 \mathrm{G}$ allele are associated with elevated plasma levels of PAI-1.

To date, a number of molecular epidemiological studies have been performed to evaluate the association between PAI-1 promoter 4G/5G polymorphism and risks for different types of tumor, including breast cancer (12-17), colorectal cancer $(3,18-20)$, ovarian cancer $(21,22)$, oral cancer $(23,24)$, endometrial cancer $(25,26)$ and other cancers $(27,28)$, in diverse populations However, the observed associations of these studies were inconsistent and a single study may be insufficient to detect a possible small effect of the polymorphism on cancer, particularly when the sample size is relatively small. Hence, we performed a meta-analysis of all eligible studies to derive a more precise estimation of the association of PAI-1 promoter $4 \mathrm{G} / 5 \mathrm{G}$ polymorphism with cancer risk. To our knowledge, no meta-analysis concerning the influence of PAI-1 4G/5G polymorphism on cancer risk has been published in the literature.

\section{Materials and methods}

Publication search. We carried out a search in PubMed, Scopus, Web of Science and Chinese National Knowledge Infrastructure (CNKI) databases with a combination of the 
following keywords: 'plasminogen activator inhibitor-1', 'PAI-1', 'SERPINE1', 'polymorphism', 'variation', 'variant', 'carcinoma', 'tumor' and 'cancer' (the last search was updated on 10th February 2012). We evaluated potentially relevant publications by examining their titles and abstracts. All studies with full text matching the eligible criteria were retrieved. Additional relevant studies were identified by a manual search of the references of retrieved articles and reviews.

Inclusion criteria. Studies included in this meta-analysis met the following criteria: a) evaluation of the link between PAI-1 promoter $4 \mathrm{G} / 5 \mathrm{G}$ polymorphism and cancer risk, b) a case-control design, c) contained sufficient published data for estimating odds ratios (ORs) and 95\% confidence intervals (CIs).

Quality assessment. The quality of each study was assessed independently by two reviewers who used the Newcastle-Ottawa Scale (NOS) (29). The NOS consists of three parameters of quality: selection, comparability, and exposure (case-control studies) or outcome (cohort studies). Scores ranged from 0 stars (worst) to 9 stars (best). Studies with a score $\geq 7$ stars were considered to be of high quality. Any discrepancies were settled by a joint re-evaluation of the original article with a third reviewer.

Data extraction. Information was extracted independently by two reviewers according to the inclusion criteria. Any disagreement was settled by consensus among the two. For each study, the following characteristics were collected: the first author's last name, year of publication, country of origin, ethnicity, numbers of genotyped cases and controls, source of control groups and genotyping methods. Different ethnic descents were categorized as Caucasian, Asian and mixed, which included more than one ethnic descent. We also contacted study authors for any missing data.

When the source of controls was not clearly defined in the paper, it was defined 'not specified' to be conservative. The ethnicity of each study population was defined as the ethnic group of $\geq 90 \%$ of the study subjects. When the paper did not specify the ethnicity of the study population, it was hypothesized based on the most frequent ethnic group in the study country.

Statistical methods. Crude ORs together with their corresponding 95\% CIs were used to calculate and assess the strength of association between PAI-1 promoter $4 \mathrm{G} / 5 \mathrm{G}$ polymorphism and cancer risk. We first estimated cancer risk associated with PAI-1 promoter $4 \mathrm{G} / 5 \mathrm{G}$ polymorphism by $4 \mathrm{G} / 4 \mathrm{G}$ and $4 \mathrm{G} / 5 \mathrm{G}$ genotypes compared with the $5 \mathrm{G} / 5 \mathrm{G}$ (co-dominant model) and then evaluated $4 \mathrm{G} / 4 \mathrm{G}+4 \mathrm{G} / 5 \mathrm{G}$ vs. $5 \mathrm{G} / 5 \mathrm{G}$, and $4 \mathrm{G} / 4 \mathrm{G}$ vs $4 \mathrm{G} / 5 \mathrm{G}+5 \mathrm{G} / 5 \mathrm{G}$, assuming the dominant and recessive effects of the variant $4 \mathrm{G}$ allele, respectively. The departure of frequencies from those expected under Hardy-Weinberg equilibrium (HWE) was assessed by Chi-square goodness-of-fit tests in controls. Stratified analyses were also performed by cancer type (if a cancer type was represented by only a single study, it was combined with the 'other cancers' group) and ethnicity.

For the heterogeneity test, a random-effect model (the DerSimonian and Laird method) (30) was used when
$\mathrm{P}<0.05$, otherwise a fixed-effect model (the Mantel-Haenszel method) (31) was used. In the random-effect model, we incorporated the random variation within the studies and the variation among the different studies, and in the fixed-effect model, we assumed that all studies came from a common population and the effect size was not significantly different among the different studies.

With regard to sensitive analyses, the influence of each study in the pooled OR was examined by repeating meta-analyses while omitting each study one at a time. We performed visual inspection of funnel plots to examine the underlying publication bias, and also used Egger's weighted regression method to calculate P for bias (32). All statistical analyses were performed with STATA 11.0 (StataCorp, TX, USA), using two-sided P-values.

\section{Results}

Summary statistics. We identified 21 articles (3,12-28,33-35) which we used to evaluate the association of PAI-1 promoter $4 \mathrm{G} / 5 \mathrm{G}$ polymorphism with risk of cancer. The study characteristics are summarized in Table I. Among the 21 eligible case-control studies, which included 8,415 cases and 9,208 controls, there were 7 breast cancer studies, 4 colorectal cancer studies, 3 ovarian cancer studies, 2 oral cancer studies, 2 endometrial cancer studies, and the others were categorized into the 'other cancer' group. Continental origin populations among these studies were as follows: 13 studies with Caucasian subjects, 7 studies with Asian subjects, and one study with more than one ethnicity (classified as mixed). Cancers were confirmed histologically in most studies. Diverse genotyping methods were used, including polymerase chain reaction-restriction fragment length polymorphism (PCR-RFLP), polymerase chain reaction-single strand conformation polymorphism (PCR-SSCP), TaqMan, sequencing, minisequencing, real-time PCR and matrix-assisted laser desorption/ionizing time-of-flight mass spectrometry (MALDI/TOF). The distribution of genotypes in the controls was consistent with HWE in all but one of the studies (35).

Quality assessment results. The NOS results showed that $81.0 \%$ of the studies were of high quality (NOS score $>6$ ), with an average NOS score of 7.6, which indicated that the methodological quality was generally good. We defined studies that scored $\geq 7$ as having high methodological quality, and we judged $4(21,22,26,35)$ of the 21 studies to be of low quality (score of 6) primarily due to the absence of a definition of controls and a lack of a description of comparability between cases and controls.

Quantitative synthesis. The overall OR with its 95\% CI revealed a statistical association between the PAI-1 promoter $4 \mathrm{G} / 5 \mathrm{G}$ polymorphism and the risk of cancer $(4 \mathrm{G} / 4 \mathrm{G}$ vs. $5 \mathrm{G} / 5 \mathrm{G}$ : $\mathrm{OR}=1.25,95 \% \mathrm{CI}=1.07-1.47, \mathrm{P}_{\text {heterogeneity }}=0.001 ; 4 \mathrm{G} / 4 \mathrm{G}$ vs. 4G/5G+5G/5G: OR=1.10, 95\% CI=1.03-1.17, $\mathrm{P}_{\text {heterogeneity }}=0.194$; 4G/4G+4G/5G vs. 5G/5G: $\mathrm{OR}=1.17,95 \% \mathrm{CI}=1.01-1.35$, $\mathrm{P}_{\text {heterogeneity }}=0.041$; Figs. 1 and 2). In the subgroup analysis by ethnicity, statistically significant elevated cancer risks were found among Caucasians $(4 \mathrm{G} / 4 \mathrm{G}$ vs. $5 \mathrm{G} / 5 \mathrm{G}$ : $\mathrm{OR}=1.39$, $95 \% \mathrm{CI}=1.12-1.74, \mathrm{P}_{\text {heterogeneity }}=0.001 ; 4 \mathrm{G} / 4 \mathrm{G}$ vs $.4 \mathrm{G} / 5 \mathrm{G}+5 \mathrm{G} / 5 \mathrm{G}$ : 


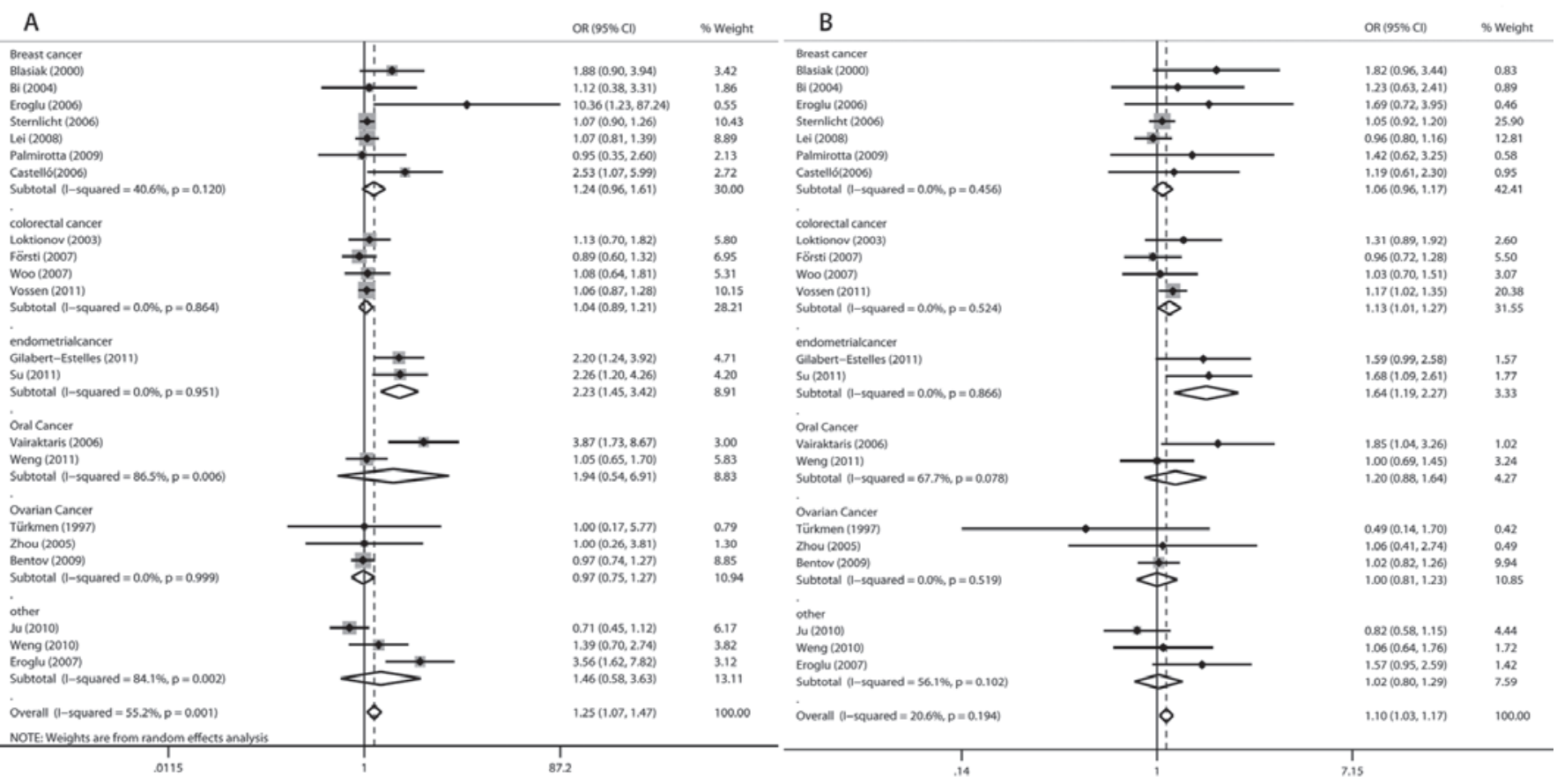

Figure 1. Forest plot of cancer risk associated with plasminogen activator inhibitor-1 (PAI-1) 4G/5G polymorphism in different ethnicities. The squares and horizontal lines correspond to the study-specific odds ratio (OR) and $95 \%$ confidence interval (CI). The area of the squares reflects the study-specific weight (inverse of the variance). The diamond represents the pooled OR and 95\% CI. (A) 4G/4G vs. 5G/5G, random-effect model used as the P-value for the heterogeneity test $<0.05$; (B) $4 \mathrm{G} / 4 \mathrm{G}$ vs. $4 \mathrm{G} / 5 \mathrm{G}+5 \mathrm{G} / 5 \mathrm{G}$.

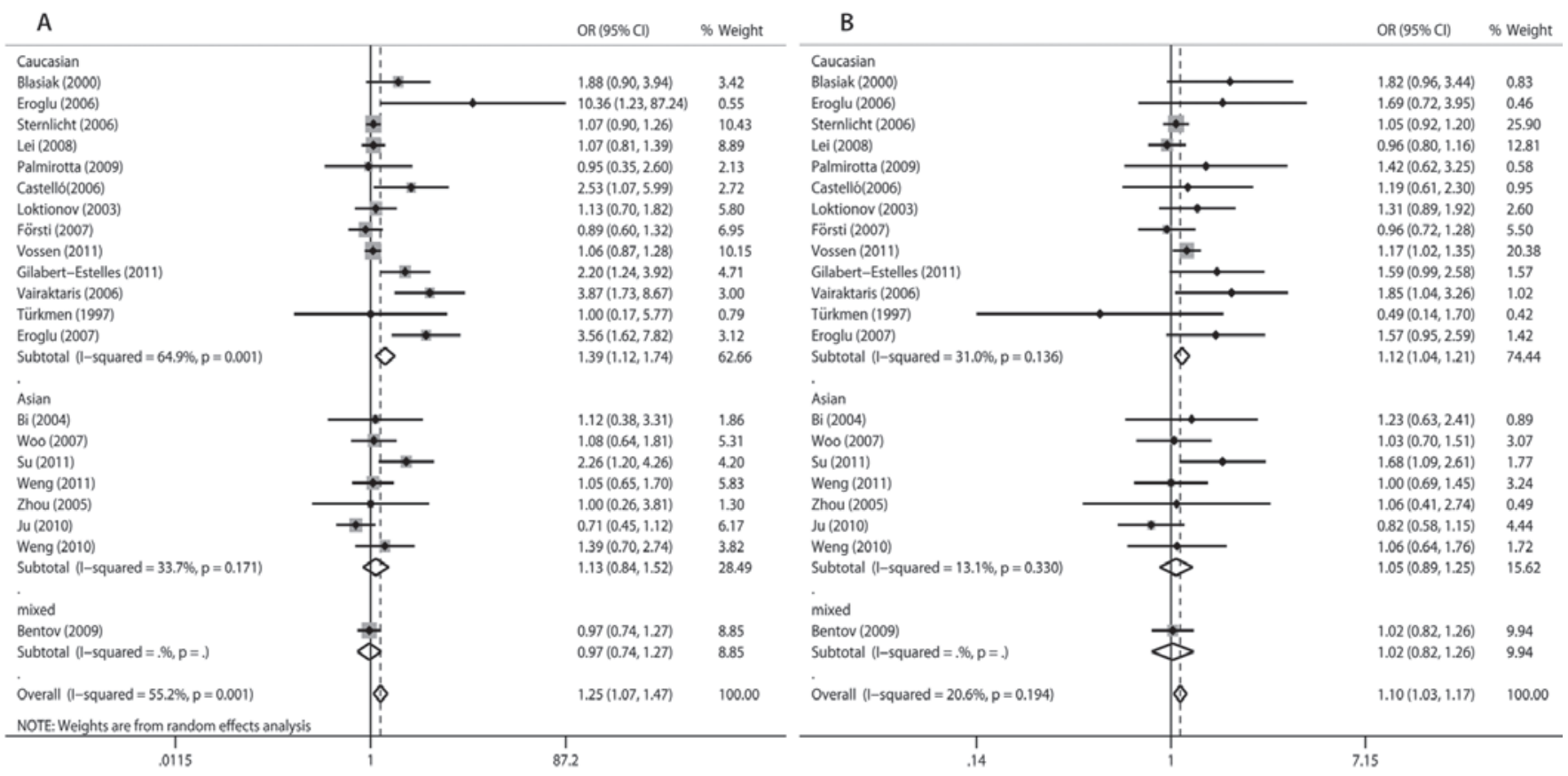

Figure 2. Forest plot of cancer risk associated with plasminogen activator inhibitor-1 (PAI-1) 4G/5G polymorphism in different types of cancer. The squares and horizontal lines correspond to the study-specific odds ratio (OR) and 95\% confidence interval (CI). The area of the squares reflects the study-specific weight (inverse of the variance). The diamond represents the pooled OR and $95 \%$ CI. (A) 4G/4G vs. 5G/5G, random-effect model used as the P-value for the heterogeneity test $<0.05$; (B) $4 \mathrm{G} / 4 \mathrm{G}$ vs. $(4 \mathrm{G} / 5 \mathrm{G}+5 \mathrm{G} / 5 \mathrm{G})$.

$\mathrm{OR}=1.12,95 \% \mathrm{CI}=1.04-1.21, \mathrm{P}_{\text {heterogeneity }}=0.136 ; 4 \mathrm{G} / 4 \mathrm{G}+4 \mathrm{G} / 5 \mathrm{G}$ vs. $5 \mathrm{G} / 5 \mathrm{G}$ : $\mathrm{OR}=1.28,95 \% \mathrm{CI}=1.04-1.57, \mathrm{P}_{\text {heterogeneity }}=0.000$; Fig. 1). Moreover, when stratifying by cancer type, significantly increased cancer risks were observed for endometrial cancer in all comparison models $(4 \mathrm{G} / 4 \mathrm{G}$ vs. $5 \mathrm{G} / 5 \mathrm{G}$ : $\mathrm{OR}=2.23$,
95\% CI=1.46-3.42, $P_{\text {heterogeneity }}=0.951 ; 4 \mathrm{G} / 5 \mathrm{G}$ vs. $5 \mathrm{G} / 5 \mathrm{G}$ : $\mathrm{OR}=1.56,95 \% \mathrm{CI}=1.08-2.25, \mathrm{P}_{\text {heterogeneity }}=0.830 ; 4 \mathrm{G} / 4 \mathrm{G}$ vs. $4 \mathrm{G} / 5 \mathrm{G}+5 \mathrm{G} / 5 \mathrm{G}: \mathrm{OR}=1.64,95 \% \mathrm{CI}=1.19-2.27, \mathrm{P}_{\text {heterogeneity }}=0.866$; $4 \mathrm{G} / 4 \mathrm{G}+4 \mathrm{G} / 5 \mathrm{G}$ vs. $5 \mathrm{G} / 5 \mathrm{G}: \mathrm{OR}=1.74,95 \% \mathrm{CI}=1.23-2.47$, $\mathrm{P}_{\text {heterogeneity }}=0.979$; Fig. 2). The details are listed in Table II. 
Table I. Characteristics of populations and cancer types of studies included in the meta-analysis.

\begin{tabular}{|c|c|c|c|c|c|c|c|c|}
\hline Study (year) & $\begin{array}{l}\text { Country } \\
\text { of origin }\end{array}$ & Ethnicity & $\begin{array}{c}\text { Source of } \\
\text { control }\end{array}$ & Cancer type & $\begin{array}{l}\text { Genotyping } \\
\text { method }\end{array}$ & $\begin{array}{c}\text { Cases } \\
\text { (no.) }\end{array}$ & $\begin{array}{l}\text { Controls } \\
\text { (no.) }\end{array}$ & HWE \\
\hline Türkmen 1997 & German & Caucasian & ns & Ovarian & PCR-RFLP & 22 & 23 & Yes \\
\hline Blasiak 2000 & Poland & Caucasian & ns & Breast & PCR-SSCP & 100 & 106 & Yes \\
\hline Loktionov 2003 & UK & Caucasian & PCC & colorectal & PCR-SSCP & 206 & 355 & Yes \\
\hline Bi 2004 & China & Asian & PCC & Breast & PCR-SSCP & 53 & 146 & No \\
\hline Zhou 2005 & China & Asian & $\mathrm{HCC}$ & Ovarian & PCR-SSCP & 52 & 30 & Yes \\
\hline Eroglu 2006 & Turkey & Caucasian & ns & Breast & PCR-SSCP & 34 & 90 & Yes \\
\hline Castellò 2006 & Spain & Caucasian & PCC & Breast & PCR-SSCP & 104 & 104 & Yes \\
\hline Sternlicht 2006 & USA & Caucasian & PCC & Breast & Minisequencing & 2,539 & 1,832 & Yes \\
\hline Vairaktaris 2006 & Greece & Caucasian & PCC & Oral & PCR-RFLP & 104 & 106 & Yes \\
\hline Eroglu 2007 & Turkey & Caucasian & ns & Mixed & PCR-SSCP & 125 & 180 & Yes \\
\hline Försti 2007 & German & Caucasian & PCC & Colorectal & Taqman & 304 & 581 & Yes \\
\hline Woo 2007 & Korea & Asian & ns & Colorectal & PCR-RFLP & 185 & 304 & Yes \\
\hline Lei 2008 & German & Caucasian & PCC & Breast & Taqman & 959 & 952 & Yes \\
\hline Bentov 2009 & Canada & Mixed & $\mathrm{HCC}$ & Ovarian & MALDI-TOF & 775 & 889 & Yes \\
\hline Palmirotta 2009 & Italy & Caucasian & PCC & Breast & Sequencing & 99 & 50 & Yes \\
\hline Ju 2010 & Korea & Asian & PCC & Gastric & MALDI-TOF & 252 & 406 & Yes \\
\hline Weng 2010 & Taiwan & Asian & $\mathrm{HCC}$ & Hepatocellular & PCR-RFLP & 102 & 344 & Yes \\
\hline $\begin{array}{l}\text { Gilabert-Estelles } \\
2011\end{array}$ & Spain & Caucasian & PCC & Endometrial & Real-time PCR & 212 & 211 & Yes \\
\hline Su 2011 & Taiwan & Asian & $\mathrm{HCC}$ & Endometrial & PCR-RFLP & 134 & 302 & Yes \\
\hline Vossen 2011 & Netherlands & Caucasian & PCC & Colorectal & Taqman & 1,801 & 1,853 & Yes \\
\hline Weng 2011 & Taiwan & Asian & $\mathrm{HCC}$ & Oral & PCR-RFLP & 253 & 344 & Yes \\
\hline
\end{tabular}

HCC, hospital-based case-control; PCC, population-based case-control; ns, not specified (source of controls was not clearly defined); PCR-RFLP, polymerase chain reaction-restriction fragment length polymorphism; PCR-SSCP, single-strand conformation polymorphism analysis of polymerase chain reaction products; MALDI-TOF, matrix-assisted laser desorption/ionizing time-of-flight mass spectrometry; HWE, Hardy-Weinberg equilibrium.
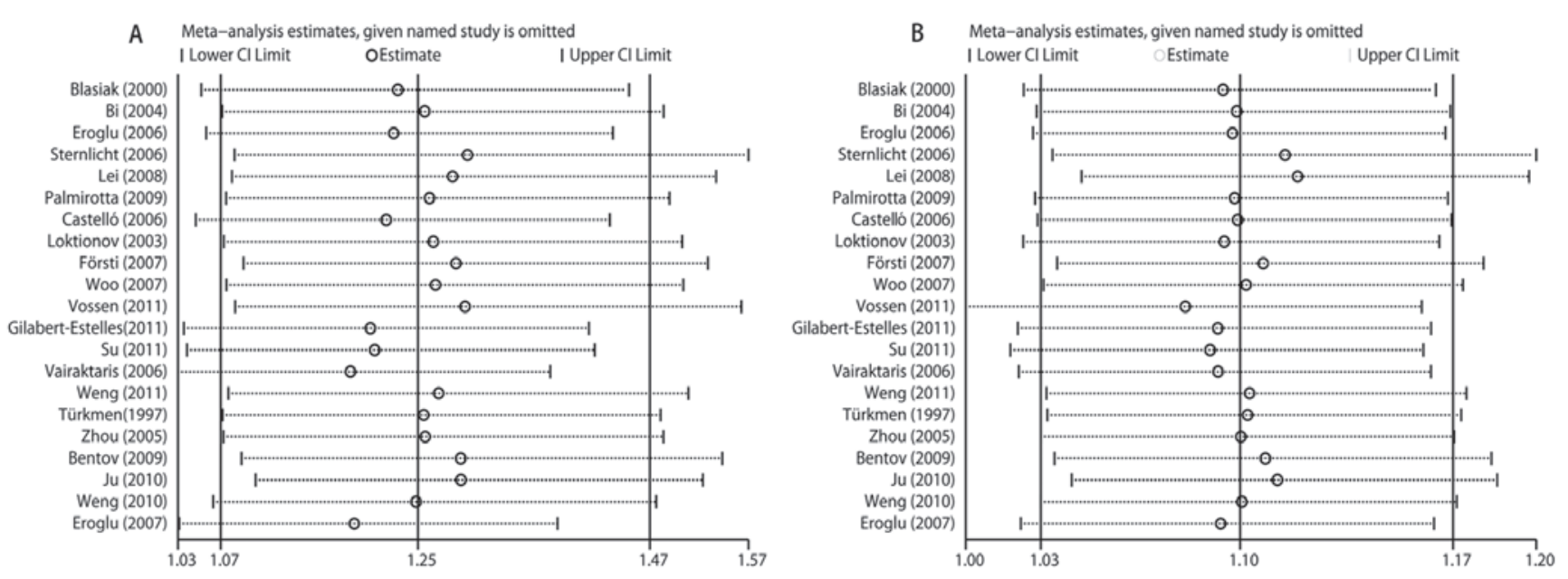

Figure 3. Influence analysis in the overall meta-analysis. The figure shows the influence of individual studies on the summary odds ratio (OR). (A) 4G/4G vs. $5 \mathrm{G} / 5 \mathrm{G}$; (B) $4 \mathrm{G} / 4 \mathrm{G}$ vs. $4 \mathrm{G} / 5 \mathrm{G}+5 \mathrm{G} / 5 \mathrm{G}$. CI, confidence interval.

Sensitivity analysis. In the sensitivity analysis (Fig. 3), the influence of each study on the pooled OR was examined by repeating the meta-analysis while omitting each study, one at a time. This procedure demonstrated that our results were reliable and robust. In addition, when excluding the studies that were not in HWE, the estimated pooled OR still did not change at all. 


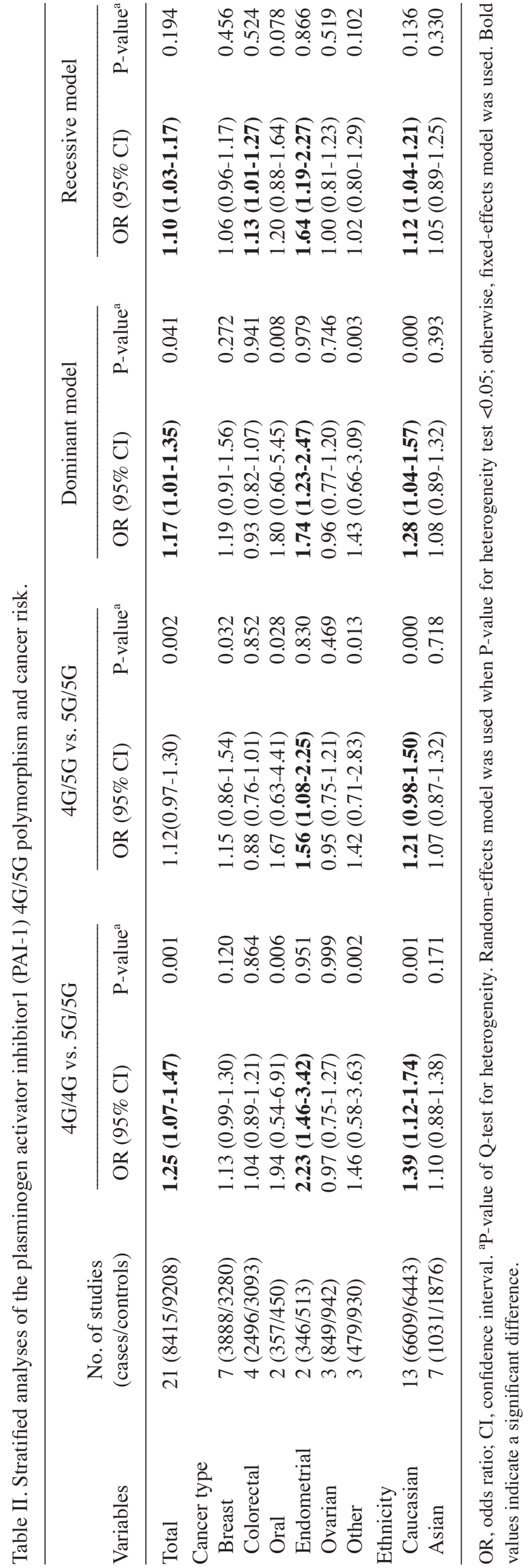

Publication bias. Publication bias was assessed by visual inspection of funnel plots in which the standard error of the $\log (\mathrm{OR})$ of each study was plotted against its $\log (\mathrm{OR})$. An asymmetric plot suggests a possible publication bias. Funnel plot asymmetry was assessed by the method of Egger's linear regression test, a linear regression approach for measuring funnel plot asymmetry on the natural logarithm scale of the OR. The significance of the intercept was determined by the t-test $(\mathrm{P}<0.05$ was considered representative of statistically significant publication bias) (32). As a result, publication bias was identified in certain comparisons $(4 \mathrm{G} / 4 \mathrm{G}$ vs. $5 \mathrm{G} / 5 \mathrm{G}$, $4 \mathrm{G} / 5 \mathrm{G}$ vs. $5 \mathrm{G} / 5 \mathrm{G}$, and $4 \mathrm{G} / 4 \mathrm{G}+4 \mathrm{G} / 5 \mathrm{G}$ vs. $5 \mathrm{G} / 5 \mathrm{G})$.

\section{Discussion}

The promoter $4 \mathrm{G} / 5 \mathrm{G}$ polymorphism is the most well-characterized PAI-1 polymorphism, but the reported associations with cancer risk among studies are inconsistent. Our present metaanalysis, incorporating 21 case-control studies $(8,415$ cases and 9,208 controls), suggests that the promoter $4 \mathrm{G} / 5 \mathrm{G}$ polymorphism is significantly associated with increased cancer risk, particularly in Caucasians.

How a promoter $4 \mathrm{G} / 5 \mathrm{G}$ polymorphism increases the risk of developing cancer is yet to be established; however, it is known that the transcription of the PAI-1 gene is affected by the presence of a guanosine insertion (5G)/deletion (4G) polymorphism at the promoter region $(13,36)$. Both $4 \mathrm{G}$ and $5 \mathrm{G}$ alleles bind a transcriptional activator, whereas the $5 \mathrm{G}$ allele also binds a repressor (36). Hence, the presence of $4 \mathrm{G} / 4 \mathrm{G}$ homozygotes enhances transcription to increase plasma PAI-1 levels, whereas $5 \mathrm{G} / 5 \mathrm{G}$ homozygotes are associated with lower levels of the inhibitor $(13,36)$. High plasma PAI-1 concentrations have been reported to be a predictive indicator of poor prognosis and shorter survival of patients with cancer (4-6,37). The PAI-1 4G/5G polymorphism has also been found to be located within the functional binding sites for the transcription factors Smad and NF- $\kappa \mathrm{B}$, which mediate the effects of two known inducers of PAI-1 expression, transforming growth factor- $\beta$ (TGF- $\beta$ ) and tissue necrosis factor- $\alpha$ (TNF- $\alpha$ ), respectively $(38,39)$.

Since tumor origin may influence the results of the metaanalyses, we performed subgroup analyses by cancer type. The association of the PAI-1 promoter $4 \mathrm{G} / 5 \mathrm{G}$ polymorphism with increased risk of cancer in this meta-analysis was significant in the endometrial cancer subgroup. In addition to the above reasons, the presence of the $4 \mathrm{G}$ allele results in a higher PAI-1 transcription response to cytokines or growth factors than the $5 \mathrm{G}$ allele, so the $4 \mathrm{G} / 5 \mathrm{G}$ polymorphism may influence tissue PAI-1 levels in endometrial cancer patients through the action of cytokines released by tumor cells (25). However, since only two independent studies with limited sample size were included in this meta-analysis, further studies with a larger number of patients are needed to explore the clinical significance of the PAI-1 4G/5G polymorphism in endometrial cancer.

Due to differences in the underlying genetic backgrounds and/or environmental and social factors of the different populations studied, the incidence of gene polymorphisms varies substantially between different racial or ethnic populations. In this meta-analysis, when stratifying by ethnicity we 
found that the association between PAI-1 promoter $4 \mathrm{G} / 5 \mathrm{G}$ polymorphism and increased risk of cancer was significant only in Caucasians, not in the Asian population. As a multifactorial disease, the factors causing cancer vary in different populations. Although the reasons for this difference remain controversial, there are several studies showing that it depends on a combination of differences in polymorphism distributions with nongenetic factors. Therefore, the functional difference of this polymorphism of PAI-1 in Caucasians and Asians may result from interactions with environmental and social factors. In addition, considering the multistage character of cancer, genetic factors may play a role at specific stages only, which may vary between populations. Therefore, larger-scale studies and combined analysis are warranted to further confirm the effect of ethnic difference in this polymorphism on cancer risks. These studies should be stratified by ethnicity, differentiated by the stage of carcinogenesis and include an assessment of interactions with environmental factors.

Additionally, heterogeneity may influence the results of meta-analyses. Evident heterogeneity between studies was observed in overall comparisons and also in certain subgroup analyses. Through the subgroup analysis, we found that the source of heterogeneity was from types of cancer and ethnicity, suggesting that tumor site and population play an important role for the same polymorphism.

When interpreting the results, the following limitations of the study should be considered. First, only published articles were included in this study. Although we conducted a thorough and comprehensive search and also contacted study authors for missing data (13), publication bias could not be completely avoided. To evaluate the results, Egger's test was performed. The results show that key publication bias may be present in this meta-analysis as there was some uncertainty with the P-value being less than 0.05 in Egger's test, hence some results should be interpreted cautiously. Secondly, lack of the original data of the reviewed studies limited our further evaluation of potential interactions, since the interactions between gene-to-gene, gene-to-environment and even different polymorphic loci of the same gene may modulate cancer risk.

Our results suggest that the PAI-1 promoter $4 \mathrm{G} / 5 \mathrm{G}$ polymorphism is a potential clinical genetic marker contributing to cancer susceptibility. Whether it could be applied to genotyping for clinical assessment requires large-scale population studies among different ethnicities and regions.

\section{Acknowledgements}

This study was supported by a grant from the National Natural Science Foundation of China (Grant No. 30900552/H1619).

\section{References}

1. Sleeman J and Steeg PS: Cancer metastasis as a therapeutic target. Eur J Cancer 46: 1177-1180, 2010.

2. Dellas C and Loskutoff DJ: Historical analysis of PAI-1 from its discovery to its potential role in cell motility and disease. Thromb Haemost 93: 631-640, 2005.

3. Loktionov A, Watson MA, Stebbings WS, Speakman CT and Bingham SA: Plasminogen activator inhibitor-1 gene polymorphism and colorectal cancer risk and prognosis. Cancer Lett 189: 189-196, 2003.
4. Harbeck N, Kates RE, Look MP, et al: Enhanced benefit from adjuvant chemotherapy in breast cancer patients classified high-risk according to urokinase-type plasminogen activator (uPA) and plasminogen activator inhibitor type $1(n=3424)$. Cancer Res 62: 4617-4622, 2002.

5. Pappot H, Pedersen AN, Brunner N and Christensen IJ: The complex between urokinase (uPA) and its type-1 inhibitor (PAI-1) in pulmonary adenocarcinoma: relation to prognosis. Lung Cancer 51: 193-200, 2006.

6. Sakakibara T, Hibi K, Koike M, et al: Plasminogen activator inhibitor-1 as a potential marker for the malignancy of gastric cancer. Cancer Sci 97: 395-399, 2006.

7. Schmitt M, Mengele K, Napieralski R, et al: Clinical utility of level-of-evidence-1 disease forecast cancer biomarkers uPA and its inhibitor PAI-1. Expert Rev Mol Diagn 10: 1051-1067, 2010.

8. Ny T, Sawdey M, Lawrence D, Millan JL and Loskutoff DJ: Cloning and sequence of a cDNA coding for the human beta-migrating endothelial-cell-type plasminogen activator inhibitor. Proc Natl Acad Sci USA 83: 6776-6780, 1986.

9. Kohler HP and Grant PJ: Plasminogen-activator inhibitor type 1 and coronary artery disease. N Engl J Med 342: 1792-1801, 2000.

10. Anvari A, Schuster E, Gottsauner-Wolf M, Wojta J and Huber K: PAI-I 4G/5G polymorphism and sudden cardiac death in patients with coronary artery disease. Thromb Res 103: 103-107, 2001.

11. Grancha S, Estelles A, Tormo G, et al: Plasminogen activator inhibitor-1 (PAI-1) promoter 4G/5G genotype and increased PAI-1 circulating levels in postmenopausal women with coronary artery disease. Thromb Haemost 81: 516-521, 1999.

12. Blasiak J and Smolarz B: Plasminogen activator inhibitor-1 (PAI-1) gene 4G/5G promoter polymorphism is not associated with breast cancer. Acta Biochim Pol 47: 191-199, 2000.

13. Castelló R, España F, Vázquez $\mathrm{C}$, et al: Plasminogen activator inhibitor- $14 \mathrm{G} / 5 \mathrm{G}$ polymorphism in breast cancer patients and its association with tissue PAI-1 levels and tumor severity. Thromb Res 117: 487-492, 2006.

14. Eroglu A, Ulu A, Cam R and Akar N: Plasminogen activator inhibitor -1 gene $4 \mathrm{G} / 5 \mathrm{G}$ polymorphism in patients with breast cancer. J BUON 11: 481-484, 2006.

15. Sternlicht MD, Dunning AM, Moore DH, et al: Prognostic value of PAI1 in invasive breast cancer: evidence that tumor-specific factors are more important than genetic variation in regulating PAI1 expression. Cancer Epidemiol Biomarkers Prev 15: 2107-2114, 2006.

16. Lei H, Hemminki K, Johansson R, et al: PAI-1 -675 4G/5G polymorphism as a prognostic biomarker in breast cancer. Breast Cancer Res Treat 109: 165-175, 2008.

17. Palmirotta R, Ferroni P, Savonarola A, et al: Prognostic value of pre-surgical plasma PAI-1 (plasminogen activator inhibitor-1) levels in breast cancer. Thromb Res 124: 403-408, 2009.

18. Försti A, Lei H, Tavelin B, et al: Polymorphisms in the genes of the urokinase plasminogen activation system in relation to colorectal cancer. Ann Oncol 18: 1990-1994, 2007.

19. Woo M, Park K, Nam J and Kim JC: Clinical implications of matrix metalloproteinase- $1,-3,-7,-9,-12$, and plasminogen activator inhibitor-1 gene polymorphisms in colorectal cancer. J Gastroenterol Hepatol 22: 1064-1070, 2007.

20. Vossen CY, Hoffmeister M, Chang-Claude JC, Rosendaal FR and Brenner H: Clotting factor gene polymorphisms and colorectal cancer risk. J Clin Oncol 29: 1722-1727, 2011.

21. Türkmen B, Schmitt M, Schmalfeldt B, et al: Mutational analysis of the genes encoding urokinase-type plasminogen activator (uPA) and its inhibitor PAI-1 in advanced ovarian cancer. Electrophoresis 18: 686-689, 1997.

22. Bentov Y, Brown TJ, Akbari MR, et al: Polymorphic variation of genes in the fibrinolytic system and the risk of ovarian cancer. PLoS One 4: e5918, 2009.

23. Vairaktaris E, Yapijakis C, Serefoglou Z, et al: Plasminogen activator inhibitor-1 polymorphism is associated with increased risk for oral cancer. Oral Oncol 42: 888-892, 2006.

24. Weng CJ, Lin CW, Chung TT, Tsai CM, Chen MK and Yang SF: Impact of uPA system gene polymorphisms on the susceptibility of environmental factors to carcinogenesis and the development of clinicopathology of oral cancer. Ann Surg Oncol 18: 805-812, 2011.

25. Gilabert-Estelles J, Ramon LA, Braza-Boils A, et al: Plasminogen activator inhibitor-1 (PAI-1) $4 \mathrm{G} / 5 \mathrm{G}$ polymorphism and endometrial cancer. Influence of PAI-1 polymorphism on tissue PAI-1 antigen and mRNA expression and tumor severity. Thromb Res 130: 242-247, 2011. 
26. Su CK, Yeh KT, Yeh CB, et al: Genetic polymorphism of the plasminogen activator inhibitor-1 is associated with an increased risk of endometrial cancer. J Surg Oncol 104: 755-759, 2011.

27. Ju H, Lim B, Kim M, et al: SERPINE1 intron polymorphisms affecting gene expression are associated with diffuse-type gastric cancer susceptibility. Cancer 116: 4248-4255, 2010.

28. Weng CJ, Tsai CM, Chen YC, et al: Evaluation of the association of urokinase plasminogen activator system gene polymorphisms with susceptibility and pathological development of hepatocellular carcinoma. Ann Surg Oncol 17: 3394-3401, 2010.

29. Wells GA, Shea B, O'Connell D, et al: The Newcastle-Ottawa Scale (NOS) for assessing the quality of nonrandomised studies in meta-analyses. Ottawa Health Research Institute: http:// www.ohri.ca/programs/clinical_epidemiology/oxford.asp, 2011. Accessed March 14, 2012.

30. DerSimonian R and Laird N: Meta-analysis in clinical trials. Control Clin Trials 7: 177-188, 1986.

31. Mantel N and Haenszel W: Statistical aspects of the analysis of data from retrospective studies of disease. J Natl Cancer Inst 22: 719-748, 1959

32. Egger M, Davey Smith G, Schneider M and Minder C: Bias in meta-analysis detected by a simple, graphical test. BMJ 315: 629-634, 1997.

33. Eroglu A, Ulu A, Cam R and Akar N: Plasminogen activator inhibitor- 1 gene $4 \mathrm{G} / 5 \mathrm{G}$ polymorphism in cancer patients. J BUON 12: 135-136, 2007.

34. Zhou X and Xia SH: The study of the PAI-1 activity and its promoter region polymorphism in ovarian cancer. Guizhou Medical Journal 29: 1072-1075, 2005.
35. Bi YT, Zheng $\mathrm{M}$ and Liang WD: The correlation between $4 \mathrm{G} /$ $5 \mathrm{G}$ polymorphism located in the promoter region of PAI-I gene and breast cancer. Chinese Journal of Birth Health \& Heredity 12: 26-27, 2004

36. Eriksson P, Kallin B, van 't Hooft FM, Bavenholm P and Hamsten A: Allele-specific increase in basal transcription of the plasminogen-activator inhibitor 1 gene is associated with myocardial infarction. Proc Natl Acad Sci USA 92: 1851-1855, 1995.

37. Ohba K, Miyata Y, Kanda S, Koga S, Hayashi T and Kanetake H: Expression of urokinase-type plasminogen activator, urokinasetype plasminogen activator receptor and plasminogen activator inhibitors in patients with renal cell carcinoma: correlation with tumor associated macrophage and prognosis. J Urol 174: 461-465, 2005.

38. Swiatkowska M, Szemraj J and Cierniewski CS: Induction of PAI-1 expression by tumor necrosis factor alpha in endothelial cells is mediated by its responsive element located in the $4 \mathrm{G} / 5 \mathrm{G}$ site. FEBS J 272: 5821-5831, 2005

39. Chen YQ, Sloan-Lancaster J, Berg DT, Richardson MA, Grinnell B and Tseng-Crank J: Differential mechanisms of plasminogen activator inhibitor-1 gene activation by transforming growth factor-beta and tumor necrosis factor-alpha in endothelial cells. Thromb Haemost 86: 1563-1572, 2001. 